\title{
Cost-effectiveness and health impact of lung cancer screening with low-dose computed tomography for never smokers in Japan and the United States: a modelling study
}

Akiko Kowada ${ }^{1,2^{*}}$ (1)

\begin{abstract}
Background: Never smokers in Asia have a higher incidence of lung cancer than in Europe and North America. We aimed to assess the cost-effectiveness of lung cancer screening with low-dose computed tomography (LDCT) for never smokers in Japan and the United States.

Methods: We developed a state-transition model for three strategies: LDCT, chest X-ray (CXR), and no screening, using a healthcare payer perspective over a lifetime horizon. Sensitivity analyses were also performed. Main outcomes were costs, quality-adjusted life-years (QALYs), life expectancy life-years (LYs), incremental cost-effectiveness ratios (ICERs), and deaths from lung cancer. The willingness-to-pay level was US\$100,000 per QALY gained.

Results: LDCT yielded the greatest benefits with the lowest cost in Japan, but the ICERs of LDCT compared with CXR were US\$3,001,304 per QALY gained for American men and US\$2,097,969 per QALY gained for American women. Cost-effectiveness was sensitive to the incidence of lung cancer. Probabilistic sensitivity analyses demonstrated that LDCT was cost-effective 99.3-99.7\% for Japanese, no screening was cost-effective 77.7\% for American men, and CXR was cost-effective 93.2\% for American women. Compared with CXR, LDCT has the cumulative lifetime potential for 60-year-old Japanese to save US\$1 17 billion, increase 2,339,349 QALYs and 3,020,102 LYS, and reduce 224,749 deaths, and the potential for 60-year-old Americans to cost US\$120 billion, increase 48,651 QALYs and 67,988 LYs, and reduce 2,309 deaths.

Conclusions: This modelling study suggests that LDCT screening for never smokers has the greatest benefits and cost savings in Japan, but is not cost-effective in the United States. Assessing the risk of lung cancer in never smokers is important for introducing population-based LDCT screening.
\end{abstract}

Keywords: Low-dose computed tomography, Never smoker, Adenocarcinoma, Lung cancer, Health economics

*Correspondence: kowadaa@gmail.com

${ }^{1}$ Department of Occupational Health, Kitasato University Graduate School of Medical Sciences, 1-15-1 Kitasato, Minami-ku, Sagamihara, Kanagawa 252-0373, Japan

Full list of author information is available at the end of the article

\section{Background}

Lung cancer is the most commonly occurring cancer in men and the third most commonly occurring cancer in women worldwide. There were 2 million new lung cancer cases in 2018 in the world [1]. Several trials strongly suggested that low-dose computed tomography (LDCT) screening efficiently detects early-stage lung cancer and reduces lung cancer mortality in heavy 
smokers. The National Lung Screening Trial (NLST) demonstrated a relative reduction in lung-cancer mortality of $20 \%$ in former and current heavy smokers ages 55 to 74 who underwent screening with LDCT, as compared with chest X-ray (CXR) [2, 3]. The NederlandsLeuvens Longkanker Screenings Onderzoek (NELSON) trial showed that lung-cancer mortality among male former and current smokers with LDCT screening was significantly lower than those with no screening [4]. The US Preventive Services Task Force (USPSTF) recommends annual LDCT screening as a secondary prevention strategy for people aged 55 to 80 years with a 30-pack-year smoking history or those who are currently smoking or quit within 15 years [5]. Currently, LDCT screening in combination with tobacco cessation is recommended to improve the prognosis of lung cancer in current heavy smokers [6]. Several costeffectiveness studies in heavy smokers also showed the superiority of LDCT screening [7-12].

Recently, as tobacco consumption has declined, the lung cancer mortality rate in men has continued to decline [13-15]. However, the proportion of never-smoking patients with non-small cell lung cancer (NSCLC) has been significantly increasing over 30 years from $15.9 \%$ in the 1970 s to $32.8 \%$ in the 2000s [16-18]. Especially, the high proportion of lung cancer in female never smokers in Asia is predominant 61\% in Eastern and 83\% in Southern Asia, compared to $15 \%$ in the United States $[19,20]$.

In Japan, lung cancer is the third most common cancer in men, the fourth most common cancer in women, and the most common cause of cancer death that is $20 \%$ of all cancer deaths. In 2017, 22,471 lung cancer cases were diagnosed, and 74,328 lung cancer deaths were reported in 2018 [21]. According to Japanese guidelines for lung cancer screening, annual population-based lung cancer screening using CXR is recommended for all people over the age of 40 [22]. However, the early detection rate of lung cancer is low, and the delay in diagnosing and treating lung cancer leads to poor prognosis. The five-year survival rate of lung cancer is $29.5 \%$ for men and $46.8 \%$ for women in Japan [21]. Nearly $90 \%$ of lung cancer in never smokers are adenocarcinomas in Japan, which can be treated with curable surgery if detected early, making them suitable for detection with LDCT screening [2325]. In the United States, about $60 \%$ of lung cancer in never smokers is also adenocarcinoma [26]. More effective lung cancer screening for never smokers is urgently needed to save lives from lung cancer. Population-based LDCT screening for never smokers has great potential to help detect significant numbers of very early-stage lung cancers, especially in Asia [23, 27]. Lung cancer screening using LDCT in never smokers is a major concern for the secondary prevention method of lung cancer.
Cost-effectiveness regarding LDCT screening for never smokers warrants evaluation as a lung cancer control measure.

In this study, we assessed the cost-effectiveness of LDCT compared with CXR and no screening to implement the optimal lung cancer screening method for never smokers in Japan, one of the high-incidence countries, and the United States, one of the low-incidence countries.

\section{Methods}

\section{Model design and structure}

We developed a state-transition model for three strategies: LDCT, CXR, and no screening (Fig. 1). We targeted four hypothetical cohorts of 60-year-old male never smokers and 60-year-old female never smokers in Japan and the United States using a healthcare payer perspective over a lifetime horizon. The main outcomes were costs, quality-adjusted life-years (QALYs), life expectancy life-years (LYs), incremental cost-effectiveness ratios (ICERs), and deaths from lung cancer. A cycle length of one year was chosen. The half-cycle correction was applied. Costs and QALYs were discounted by 3\% year [28]. We performed decision-analytical calculations using TreeAge Pro (TreeAge Software Inc., Williamstown, Massachusetts).

In the model for lung cancer screening using LDCT or CXR, the individual receives LDCT or CXR. If LDCT or CXR is true positive and lung cancer is diagnosed by subsequent chest CT bronchoscopy with biopsy of lung tissue, the individual receives the standard treatment of lung cancer followed by the lung cancer treatment

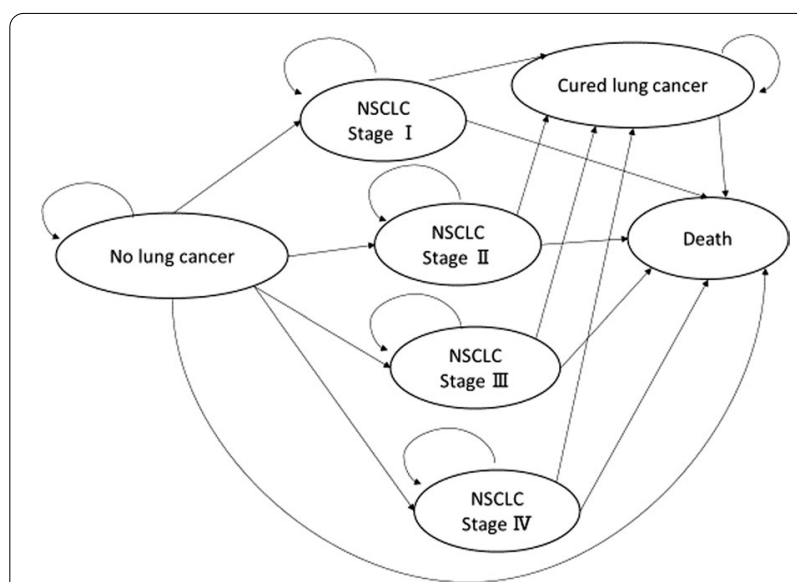

Fig. 1 Schematic depiction of a Markov cycle tree in a state-transition model. Health states in the model are indicated with ovals. Over the course of a year-long model cycle, transitions between one health state and another may occur, which are indicated by pointing arrowheads. NSCLC non-small cell lung cancer 
guidelines: surgery, or surgery combined with radiotherapy, or chemotherapy combined with radiotherapy, or chemotherapy combined with palliative care depending on the stage of cancer in Japan [29], and receives the standard treatment of lung cancer based on the Surveillance, Epidemiology, and End Results (SEER)-Medicare database in the United States [30]. The individual with false positive results continues to undergo subsequent chest CT bronchoscopy with a biopsy of lung tissue but has negative results and no treatment of lung cancer. If LDCT or CXR is true negative, the individual returns to follow-up screening. The false negative results in lung cancer patients lead to LDCT or CXR in the following year. In any of the states, all individuals were at risk of allcause mortality. We assume that the small cell lung cancer rate in never smokers is $0 \%$ in the model [31].

In no screening, we assume the stage detection proportions of lung cancer in Japanese from Japanese cancer statistics and those in Americans from literature [30, 32].

As this was a modelling study with all inputs and parameters derived from the published literature, cancer statistics, and vital statistics, ethics approval was not required.

\section{Costs, clinical probabilities, epidemiological parameters}

Costs for Japanese never smokers were based on the direct costs of screening tests and cancer treatments from the Japanese national fee schedule [33], and were adjusted to 2019 Japanese yen, using the medical care component of the Japanese consumer price index and were converted to US dollars, using the Organisation for Economic Co-operation and Development (OECD) purchasing power parity rate in 2020 (US $\$ 1=¥ 103.4$ ) [34]. The indirect costs, such as visits to inpatients and outpatients, the infrastructure, and medical staffs, were excluded. Costs for American never smokers were based on Medicare [35-37]. All costs were discounted by 3\% $[28,38]$.

Clinical probabilities and epidemiological parameters were collected using MEDLINE from 2001 to August 7, 2021, Japanese cancer statistics, and SEER cancer statistics to estimate input parameters for the models (Table 1). The incidence of lung cancer, lung cancer mortality specific to lung cancer stage, stage detection proportion of lung cancer-specific to the screening methods, and the other mortality rate were estimated by the literature, cancer statistics, vital statistics, and life tables [16, $18,21,23,26,30,32,39,40]$. Since we hypothesized that the diagnostic capability of radiologists in both countries would be equal, we assumed that the stage detection proportion of lung cancer in LDCT and CXR screening was the same in both countries. The sensitivity and specificity of LDCT and CXR screenings were derived from the literature [41]. The adherence rate of the available screening methods was assumed to be $100 \%$. We considered the cumulative increased radiogenic risk of cancer from repeated annual LDCT in the model $[42,43]$.

\section{Health state utilities}

The following seven health states were included to represent possible clinical states in the Markov model: No lung cancer, stage I in non-small cell lung cancer (NSCLC), stage II in NSCLC, stage III in NSCLC, stage IV in NSCLC, cured lung cancer, and death (Fig. 1). Health state utilities were sourced from the literature $[44,45]$. The QALYs were calculated by applying health state utility weights. The annual discounting of the utility was set at a rate of $3 \%[28,38]$.

\section{Sensitivity analyses}

We performed one-way sensitivity analyses to determine which strategy was more cost-effective when we tested a single variable over a wide range of possible values while holding all other variables constant. We used US $\$ 100,000$ per QALY gained thresholds for the willingness-to-pay thresholds [46]. Probabilistic sensitivity analyses using a second-order Monte-Carlo simulation for 10,000 trials were conducted to assess the impact of uncertainty. The uncertainty had a beta distribution in clinical probabilities and accuracies, and a log-normal distribution in costs.

\section{Results \\ Base-case analysis}

In a base-case analysis, LDCT yielded the greatest benefits with the lowest costs in Japan (men, US $\$ 20,446$, 17.8812 QALYs, 18.0655 LYs; women, US $\$ 30,065,17.665$ QALYs, 17.9603 LYs) (Table 2). In the United States, LDCT was not cost-effective compared to CXR and no screening, with the ICERs of LDCT over US $\$ 100,000$ per QALY gained (Table 2).

\section{Sensitivity analyses}

Cost-effectiveness was sensitive to the incidence of lung cancer. In Japan, LDCT was more cost-effective than CXR when the incidence of lung cancer was higher than 0.00135 for men and 0.00134 for women (Fig. 2a, b). In the United States, CXR was more cost-effective than no screening when the incidence of lung cancer was over 0.00016 for men and 0.00014 for women (Fig. 2c, d). Probabilistic sensitivity analysis with 10,000 Monte Carlo simulations demonstrated that LDCT was costeffective $99.3 \%$ for Japanese men (Fig. 3a) and $99.7 \%$ for Japanese women (Fig. 3b). The probability of no screening was $77.7 \%$ for American men (Fig. 3c) and the probability of CXR was $93.2 \%$ for American women at a 
Table 1 Baseline estimates for selected variables in never smokers

\begin{tabular}{|c|c|c|c|}
\hline Variable & Baseline value & Sensitivity analysis range & Reference \\
\hline \multicolumn{4}{|c|}{ Incidence of lung cancer in 60-year-old never smokers in Japan } \\
\hline Women & 0.0152 & $0.001-0.03$ & \multirow[t]{2}{*}{ [23] } \\
\hline Men & 0.009 & $0.001-0.03$ & \\
\hline \multicolumn{4}{|l|}{ Stage-specific 5-year survival rate in Japan } \\
\hline Stage 1 & 0.812 & $0.7-0.85$ & \multirow[t]{4}{*}[21]{} \\
\hline Stage II & 0.463 & $0.3-0.6$ & \\
\hline Stage III & 0.223 & $0.15-0.5$ & \\
\hline Stage IV & 0.051 & $0.01-0.1$ & \\
\hline \multicolumn{4}{|c|}{ Stage detection proportions of lung cancer in no screening in Japan } \\
\hline Stage I & 0.22 & $0.1-0.6$ & \multirow[t]{4}{*}{ [32] } \\
\hline Stage II & 0.06 & $0-0.2$ & \\
\hline Stage III & 0.21 & $0.1-0.3$ & \\
\hline Stage IV & 0.51 & $0.3-0.7$ & \\
\hline \multicolumn{4}{|l|}{ Costs in Japan, US\$ } \\
\hline CXR & 28.5 & $14.3-57.0$ & \multirow[t]{7}{*}{ [33] } \\
\hline LDCT & 195.7 & $97.9-391.4$ & \\
\hline Bronchoscopy with CT-guided lung biopsy & 906.2 & $453.1-1812.4$ & \\
\hline Treatment of lung cancer, Stage I & 25,835 & $12,918-51,670$ & \\
\hline Treatment of lung cancer, Stage II & 37,758 & $18,879-75,516$ & \\
\hline Treatment of lung cancer, Stage III & 48,688 & $24,344-97,376$ & \\
\hline Treatment of lung cancer, Stage IV & 264,308 & $132,154-528,616$ & \\
\hline \multicolumn{4}{|c|}{ Incidence of lung cancer in 60-year-old never smokers in the United States } \\
\hline Women & 0.000207 & $0.000135-0.000311$ & \multirow[t]{2}{*}{ [26] } \\
\hline Men & 0.000137 & $0.00009-0.000215$ & \\
\hline \multicolumn{4}{|c|}{ Stage-specific 5-year survival rate in the United States } \\
\hline Stage I & 0.75 & $0.7-0.85$ & \multirow[t]{4}{*}[16,40]{} \\
\hline Stage II & 0.53 & $0.3-0.6$ & \\
\hline Stage III & 0.41 & $0.15-0.5$ & \\
\hline Stage IV & 0.07 & $0.01-0.1$ & \\
\hline \multicolumn{4}{|c|}{ Stage detection proportions of lung cancer in no screening in the United States } \\
\hline Stage I & 0.24 & $0.1-0.6$ & \multirow[t]{4}{*}[30]{} \\
\hline Stage II & 0.07 & $0-0.2$ & \\
\hline Stage III & 0.28 & $0.1-0.3$ & \\
\hline Stage IV & 0.41 & $0.3-0.7$ & \\
\hline \multicolumn{4}{|l|}{ Costs in the United States, US\$ } \\
\hline CXR & 42.3 & $21.2-84.6$ & \multirow[t]{7}{*}[35-37]{} \\
\hline LDCT & 254.6 & $127.3-509.2$ & \\
\hline Bronchoscopy with CT-guided lung biopsy & 681.0 & $340.5-1362.0$ & \\
\hline Treatment of lung cancer, Stage I & 20,984 & $10,492-41,968$ & \\
\hline Treatment of lung cancer, Stage II & 20,984 & $10,492-41,968$ & \\
\hline Treatment of lung cancer, Stage III & 37,987 & $18,994-75,974$ & \\
\hline Treatment of lung cancer, Stage IV & 82,601 & $41,301-165,202$ & \\
\hline \multicolumn{4}{|c|}{ Stage detection proportions of lung cancer in CXR screening in Japan and the United States } \\
\hline Stage 1 & 0.61 & $0.4-0.7$ & \multirow[t]{4}{*}[39]{} \\
\hline Stage II & 0.07 & $0-0.2$ & \\
\hline Stage III & 0.17 & $0.1-0.3$ & \\
\hline Stage IV & 0.15 & $0.1-0.3$ & \\
\hline \multicolumn{4}{|c|}{$\begin{array}{l}\text { Stage detection proportions of lung cancer in LDCT screening in Japan and the United } \\
\text { States }\end{array}$} \\
\hline Stage 1 & 0.96 & $0.8-1.0$ & {$[23]$} \\
\hline
\end{tabular}


Table 1 (continued)

\begin{tabular}{|c|c|c|c|}
\hline Variable & Baseline value & Sensitivity analysis range & Reference \\
\hline Stage II & 0.01 & $0-0.1$ & \\
\hline Stage III & 0.03 & $0-0.1$ & \\
\hline Stage IV & 0.01 & $0-0.1$ & \\
\hline \multicolumn{4}{|l|}{ Accuracies (\%) } \\
\hline Sensitivity of CXR & 73.5 & $67.2-79.8$ & {$[41]$} \\
\hline Specificity of CXR & 91.3 & $91.0-91.6$ & \\
\hline Sensitivity of LDCT & 93.8 & $90.6-96.3$ & \\
\hline Specificity of LDCT & 73.4 & $72.8-73.9$ & \\
\hline \multicolumn{4}{|l|}{ Utilities } \\
\hline Healthy & 1 & N/A & {$[44]$} \\
\hline Stage I lung cancer & 0.87 & $0.7-0.9$ & \\
\hline Stage II lung cancer & 0.87 & $0.7-0.9$ & \\
\hline Stage III lung cancer & 0.77 & $0.6-0.8$ & \\
\hline Stage IV lung cancer & 0.57 & $0.3-0.6$ & \\
\hline Cured lung cancer & 0.9 & $0.7-0.9$ & \\
\hline Dead & 0 & N/A & \\
\hline \multicolumn{4}{|c|}{ Cumulative increased radiogenic risk of cancer from repeated annual LDCT (\%) } \\
\hline Women & 0.30 & N/A & {$[42]$} \\
\hline Men & 0.13 & N/A & \\
\hline
\end{tabular}

LDCT low-dose computed tomography, CXR chest X-ray, N/A not applicable

willingness-to-pay level of US\$100,000 per QALY gained (Fig. 3d).

\section{Economic and health outcomes}

In the Markov cohort analysis, for 13.05 million 60-yearold Japanese never smokers, LDCT has a cumulative lifetime potential to save US $\$ 117$ billion, increase 2,339,349 QALYs and 3,020,102 LYs, and reduce 224,749 deaths, compared with CXR. For 31.88 million 60-year-old American never smokers, LDCT has a cumulative lifetime potential to cost US $\$ 120$ billion, increase 48,651 QALYs and 67,988 LYs, and reduce 2,309 deaths, compared with CXR (Table 3).

\section{Discussion}

This study demonstrates that LDCT is cost-savings with the greatest benefits in Japan, but is not cost-effective in the United States. Cost-effectiveness is sensitive to the incidence of lung cancer. LDCT is superior to CXR when the incidence of lung cancer is greater than 0.001 in Japan, one of high-incidence countries. CXR is superior to no screening when the incidence of lung cancer is greater than 0.0002 in the United States, one of lowincidence countries. These advantages are stronger in women than in men. The main reasons for the superior cost-effectiveness of LDCT in Japan are a high detection rate of stage I with a low mortality rate, and a high sensitivity of LDCT compared to CXR. Adenocarcinoma is a predominant histologic subtype of lung cancer in female never smokers [23, 47]. LDCT screening has excellent accuracy in detecting small peripheral adenocarcinomas [48].

To the best of our knowledge, this study is the first cost-effectiveness analysis of LDCT screening for never smokers in the world.

LDCT screening is one of the key screening methods to increase chances of early lung cancer detection with curable treatment and improve health outcomes for never smokers [23, 49]. Sex, age, family history, and the results of the baseline LDCT-scan are also important factors to conduct LDCT screening in never-smokers [49]. The findings of this study suggest that LDCT screening for never smokers, especially women, would be cost-effective in high-incidence countries.

LDCT screening has several disadvantages. Low specificity of LDCT leads to false positive and overdiagnosis. We should be aware of the potential of psychological distress, anxiety, harm caused by false-positive results, and overdiagnosis with unnecessary invasive testing for individuals who choose LDCT screening [50, 51]. Radiationrelated cancer by radiation exposure to LDCT screening is also a major concern [52]. Future development of CT diagnostic equipment is expected to reduce radiation exposure during testing.

To introduce population-wise LDCT screening into the national policy, the accuracy of LDCT diagnosis 


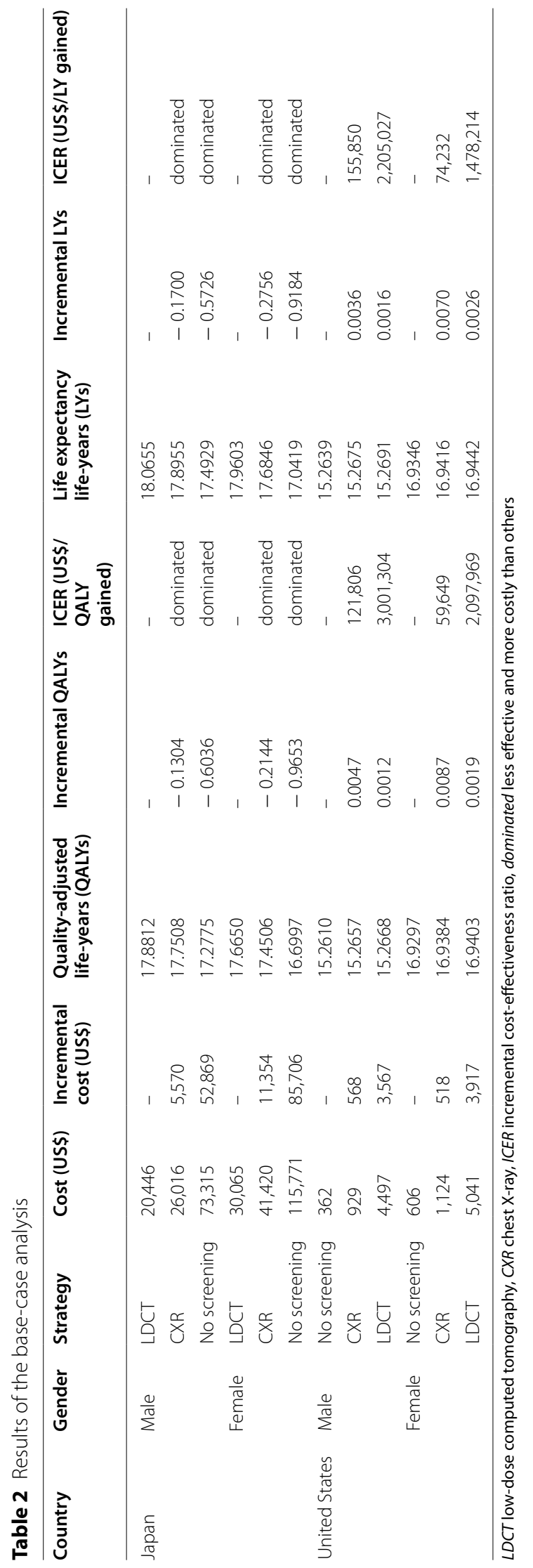




\section{(A)}

Tornado Analysis (Net Benefits)

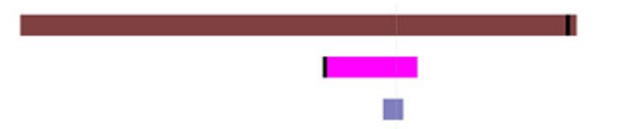

Incidence of lung cancer (0.001-0.03)

- Stage I detection proportion of LDCT (0.8-1.0)

- Cost of LDCT (97.9-391.4)

- Sensitivity of LDCT (0.906-0.963)

1

Cost of lung cancer treatment Stage $4(132,154-528,616)$

- Cost of lung cancer treatment Stage $3(24,344-97,376)$

Cost of lung cancer treatment Stage $2(18,879-75,516)$

Utility of Stage3 (0.6-0.8)

Utility of Stage4 $(0.3-0.6)$

Utility of Stage2 (0.7-0.9)

Specificity of LDCT (0.728-0.739)

Specificity of CXR (0.91-0.916)

- Sensitivity of CXR (0.672-0.798)

- Stage I detection proportion of no screening (0.1-0.6)

- Stage I detection proportion of CXR (0.4-0.7)

Cost of CXR (14.3-57.0)

EV: 1767671,448956882

$\begin{array}{lllllllll}1660000 & 1680000 & 1700000 & 1720000 & 1740000 & 1760000 & 1780000 & 1800000 & 1820000\end{array}$

(B)

Tornado Analysis (Net Benefits)

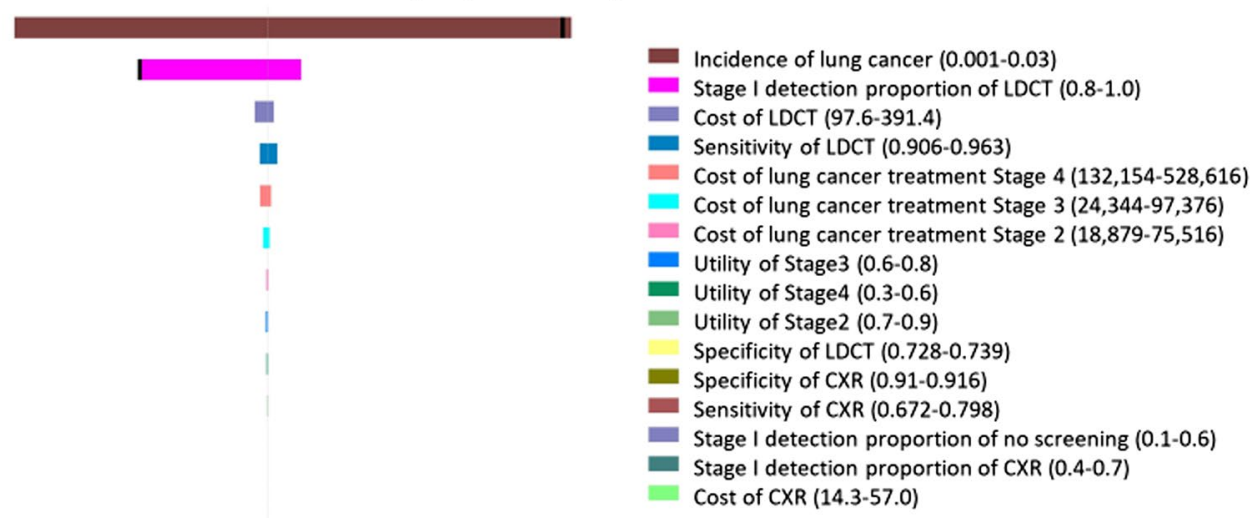

EV: 1736435.1067974968

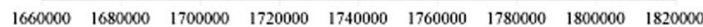

Fig. 2 Tornado diagrams of one-way sensitivity analysis. a Male never smokers in Japan, b Female never smokers in Japan, c Male never smokers in the United States, $\mathbf{d}$ Female never smokers in the United States. Tornado bars display for each variable to show how the net benefit of the optimal alternate variables change. Heavy vertical lines identify threshold points. LDCT low-dose computed tomography, CXR chest X-ray, EV expected value

must be ensured regardless of the difference in the physician's capability to diagnose. In the future, artificial intelligence technology will play an important role in ensuring the accuracy of LDCT diagnosis of lung cancer and filling in diagnostic errors. In addition, new biomarkers can help diagnose the malignancy of early pulmonary tumors [53].

The main pathogenesis and carcinogenesis of lung cancer in never smoker are associated with passive smoking history, lung cancer family history, kitchen fume, dust exposure, occupational exposure, radon gas, history of pulmonary infection and tuberculosis, chronic obstructive pulmonary disease, indoor air pollution, ionizing radiation, age, oncogenic viruses, inherited genetic susceptibility, and PM2.5 [54-60].

This study has several limitations. First, we assumed the same stage detection rates of lung cancer in CXR screening and LDCT screening in Japan and the United States. 


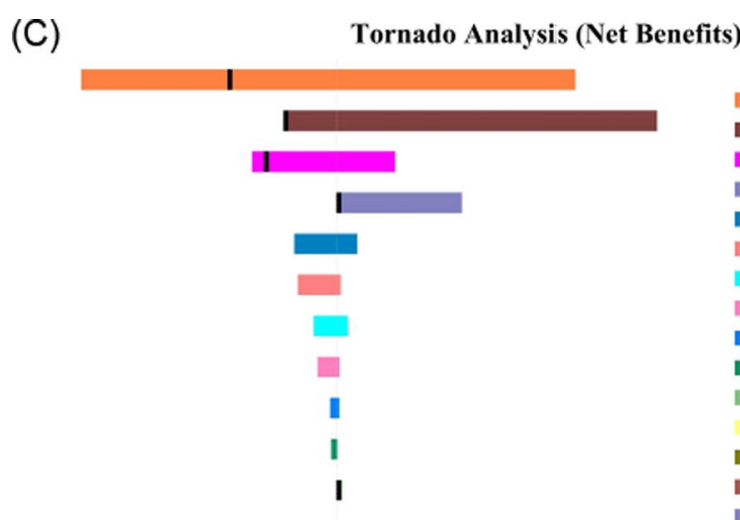

Incidence of lung cancer (0.00009-0.000215)

Stage I detection proportion of no screening $(0.1-0.6)$

Cost of lung cancer treatment Stage $4(41,301-165,202)$

Cost of CXR (21.2-84.6)

Cost of lung cancer treatment Stage $3(18,994-75,974)$

Utility of Stage 4 (0.3-0.6)

Cost of lung cancer treatment Stage $1(10,492-41,968)$

Sensitivity of CXR (0.672-0.798)

Utility of Stage 3 (0.6-0.8)

Cost of lung cancer treatment Stage $2(10,492-41,968)$

- Utility of Stage2 (0.7-0.9)

Stage I detection proportion of CXR (0.4-0.7)

Specificity of CXR (0.91-0.916)

- Sensitivity of LDCT (0.906-0.963)

- Stage I detection proportion of LDCT (0.8-1.0)

- Cost of LDCT (127.3-509.2)

Specificity of LDCT (0.728-0.739)

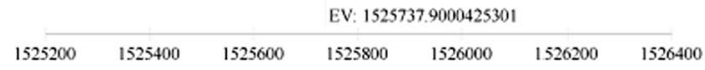

(D)

Tornado Analysis (Net Benefits)

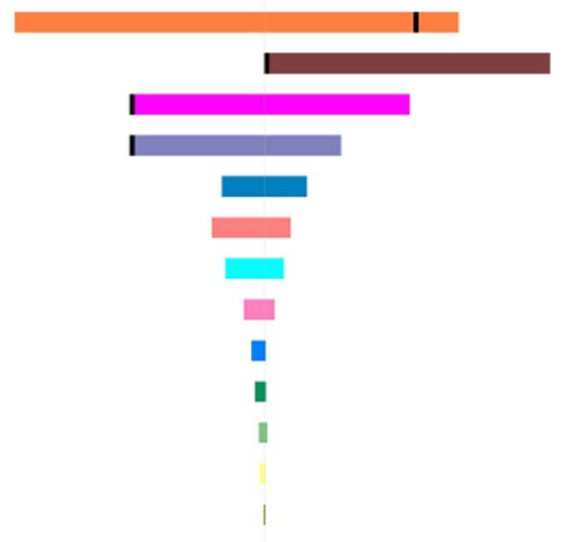

- Incidence of lung cancer (0.000135-0.000311)

- Stage I detection proportion of no screening (0.1-0.6)

- Cost of CXR (21.2-84.6)

Stage I detection proportion of CXR (0.4-0.7)

- Sensitivity of CXR (0.672-0.798)

Cost of lung cancer treatment Stage $1(10,492-41,968)$

- Cost of lung cancer treatment Stage $4(41,301-165,202)$

Cost of lung cancer treatment Stage $3(18,994-75,974)$

Utility of Stage4 (0.3-0.6)

Utility of Stage3 (0.6-0.8)

Cost of lung cancer treatment Stage $2(10,492-41,968)$

Utility of Stage2 (0.7-0.9)

- Specificity of CXR (0.91-0.916)

- Sensitivity of LDCT (0.906-963)

Stage I detection proportion of LDCT (0.8-1.0)

Cost of LDCT (127.3-509.2)

Specificity of LDCT $(0.728-0.739)$

EV: 1692715.2466841342

Fig. 2 continued

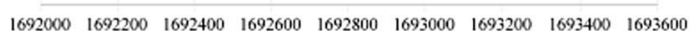

Further prospective cohort studies are needed to determine the differences in lung cancer stage detection rates by LDCT and CXR between Japan and the United States. Second, the age-related increase in lung cancer mortality was not considered in the models. Third, the sensitivity and specificity of LDCT and CXR were not based on meta-analyses [41]. However, we performed one-way sensitivity analyses for the sensitivities and specificities of the screening methods and showed that results were not sensitive to the accuracy of the screening methods.
Fourth, the adherence rates of the screening methods were assumed to be $100 \%$. The difference in compliance rates for LDCT and CXR screening was not taken into account. Fifth, we considered only the cost of bronchoscopy with CT-guided lung biopsy as the costs of diagnostic procedures in this model. Sixth, the use of microRNA signatures in whole blood samples complements diagnostic imaging, sputum cytology, and biopsy tests for lung cancer diagnosis [61]. Further cost-effective analysis of microRNAs for lung cancer screening is needed. Seventh, 


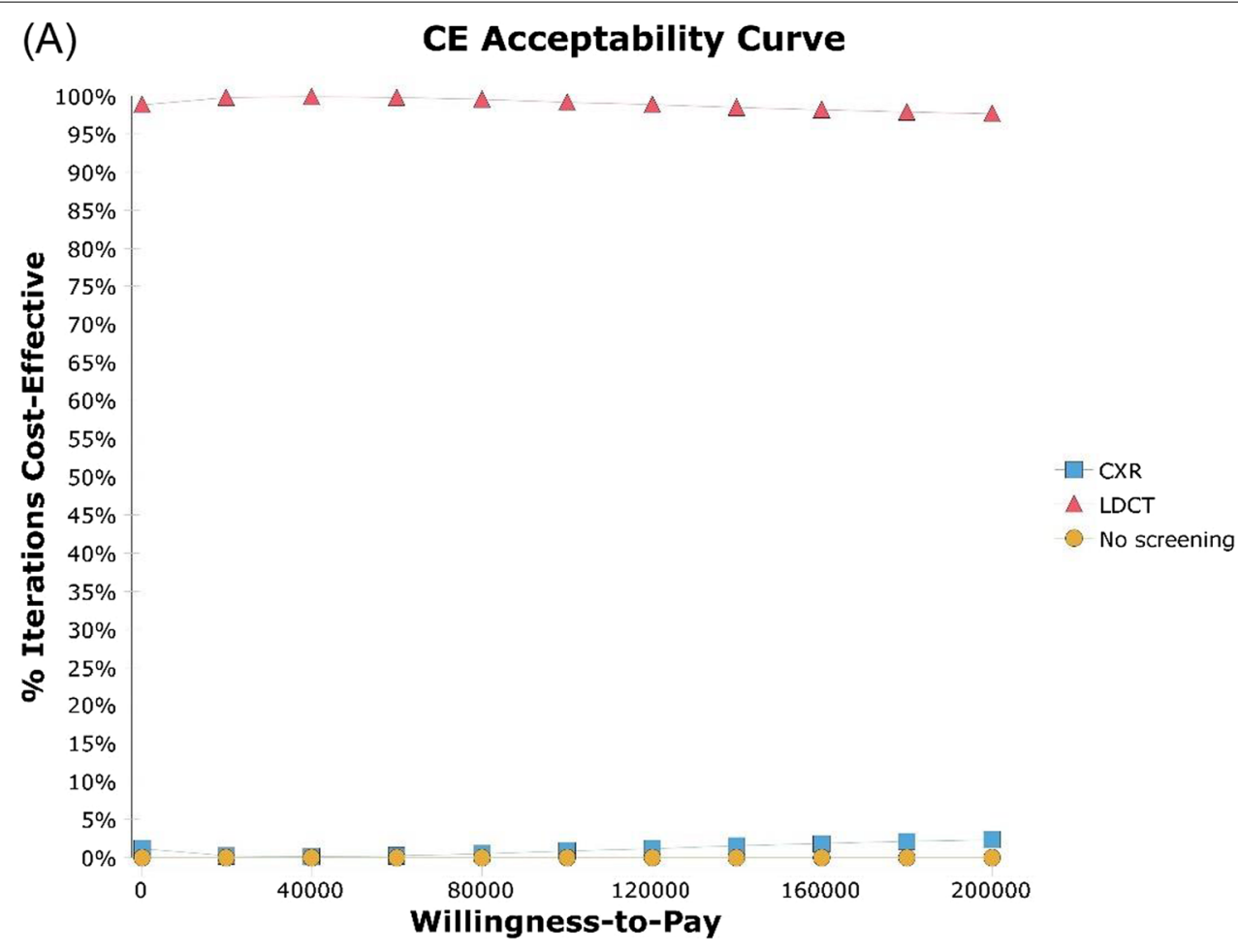

(B) CE Acceptability Curve

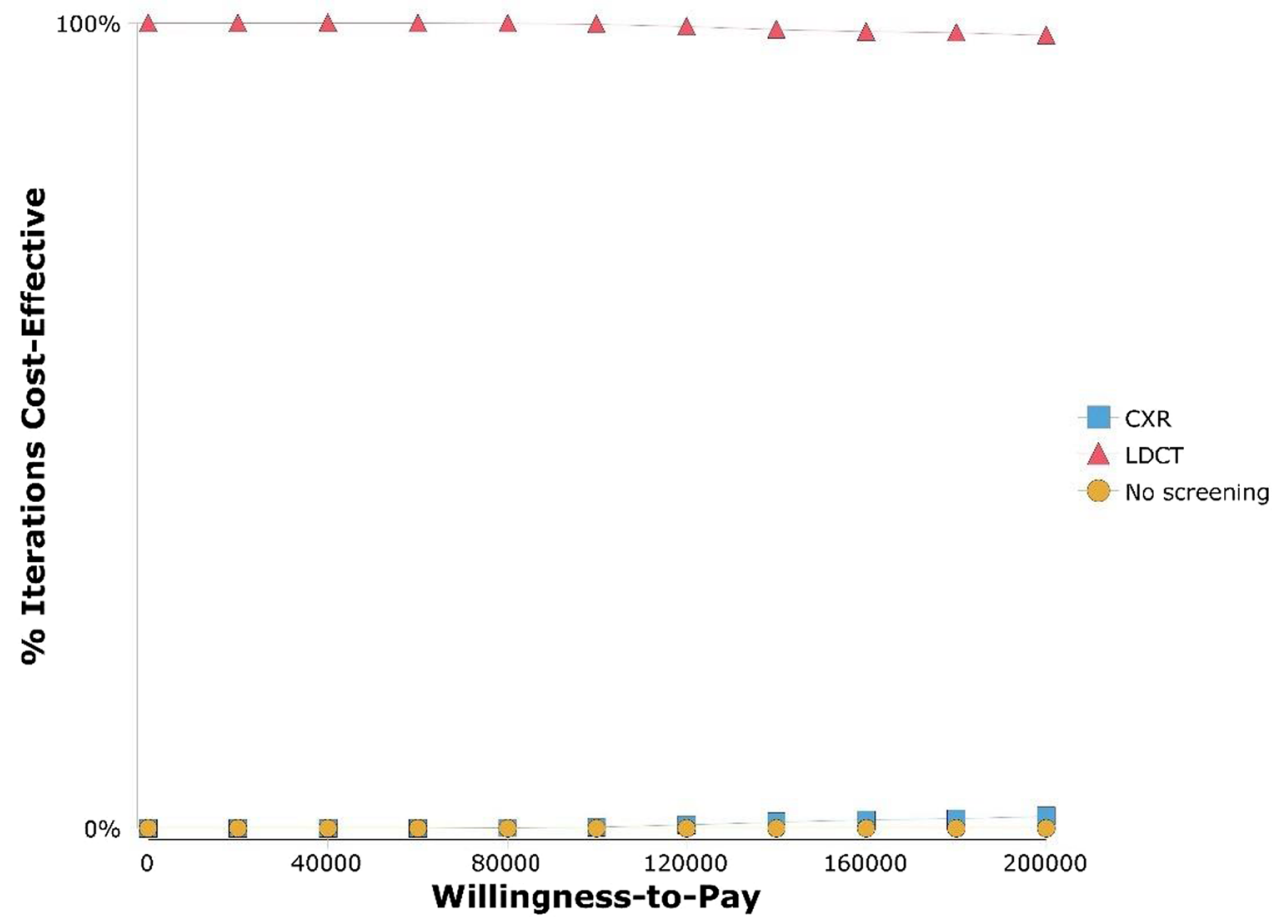

Fig. 3 Cost-effectiveness acceptability curves. a Male never smokers in Japan, b Female never smokers in Japan, c Male never smokers in the United States, d Female never smokers in the United States. The probabilistic sensitivity analysis analyzed 10,000 simulations of models with randomly changed input parameters to understand how parameter uncertainty affects model results. The $x$-axis represents the willingness-to-pay threshold (US\$ per QALY gained). LDCT low-dose computed tomography, CXR chest X-ray, QALY quality-adjusted life-year 
Kowada BMC Pulmonary Medicine

(2022) 22:19

Page 10 of 13

(C)

CE Acceptability Curve

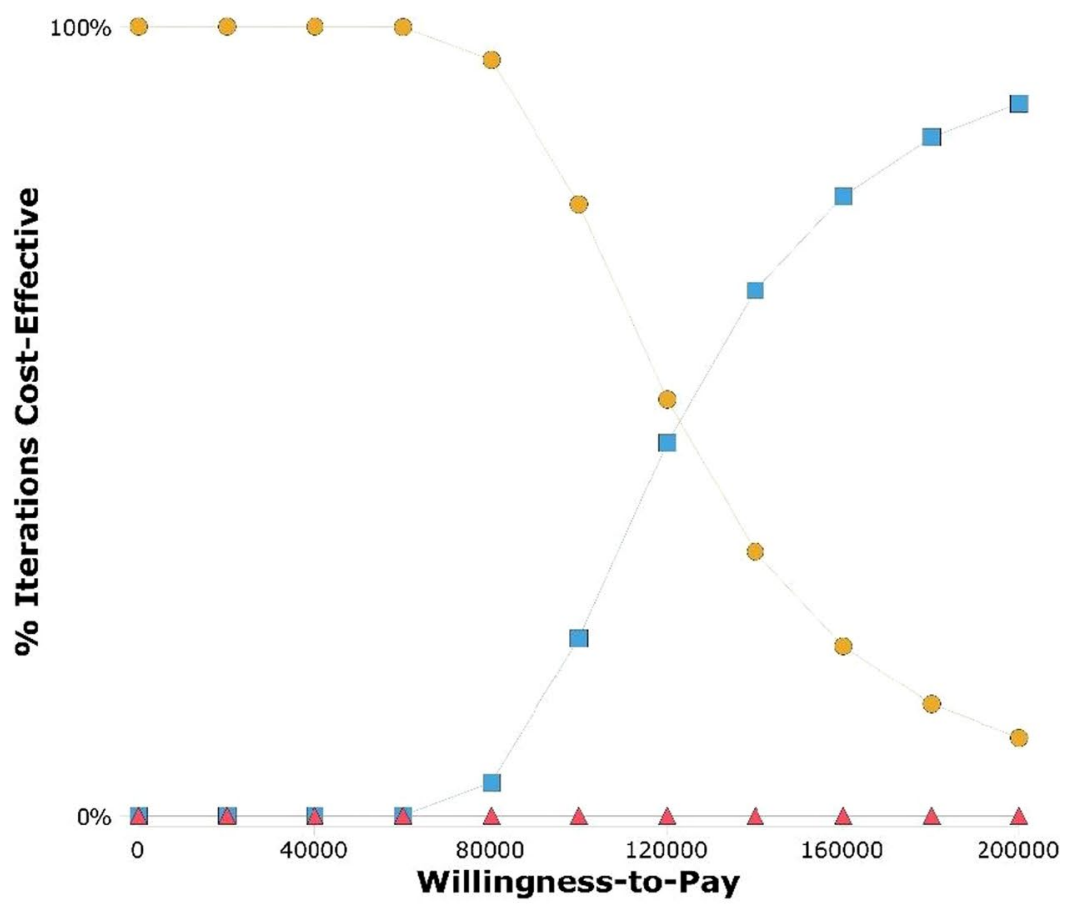

CXR

LDCT

No screening

(D) CE Acceptability Curve

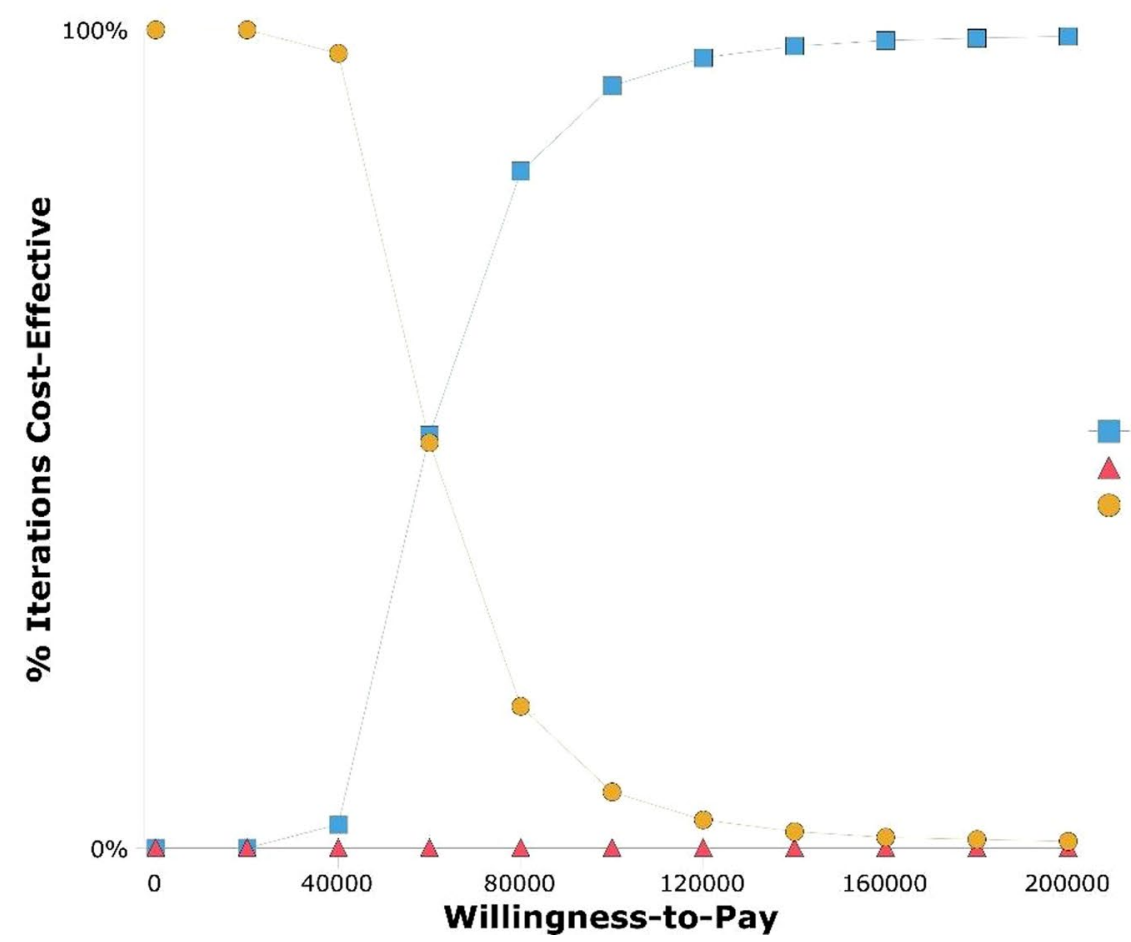

Fig. 3 continued

CXR

LDCT

No screening 
Table 3 Cumulative lifetime economic and health outcomes of LDCT

\begin{tabular}{|c|c|c|c|c|c|c|c|}
\hline Country & Gender & $\begin{array}{l}60 \text {-year-old } \\
\text { individuals } \\
\text { (n) }\end{array}$ & Cost-saving (US\$) & QALYs gain (QALYs) & LYs gain (LYs) & $\begin{array}{l}\text { Deaths averted } \\
\text { lung cancer (\%) }\end{array}$ & $\begin{array}{l}\text { Deaths averted } \\
\text { lung cancer }(\mathrm{n})\end{array}$ \\
\hline \multicolumn{8}{|c|}{ Compared with CXR } \\
\hline \multirow[t]{2}{*}{ Japan } & Male & $5,463,770$ & $30,435,384,408$ & 712,476 & 928,841 & 1.24 & 67,719 \\
\hline & Female & $7,588,028$ & $86,157,505,123$ & $1,626,873$ & $2,091,261$ & 2.07 & 157,030 \\
\hline \multirow[t]{2}{*}{ United States } & Male & $14,904,704$ & $-53,169,550,579$ & 16,395 & 23,848 & 0.005 & 750 \\
\hline & Female & $16,977,059$ & $-66,502,535,515$ & 32,256 & 44,140 & 0.009 & 1,559 \\
\hline \multicolumn{8}{|c|}{$\begin{array}{l}\text { Compared with no screen- } \\
\text { ing }\end{array}$} \\
\hline \multirow[t]{2}{*}{ Japan } & Male & $5,463,770$ & $288,864,056,130$ & $3,298,478$ & $3,128,555$ & 7.04 & 384,736 \\
\hline & Female & $7,588,028$ & $650,338,010,162$ & $7,324,723$ & $6,968,845$ & 10.93 & 829,238 \\
\hline \multirow[t]{2}{*}{ United States } & Male & $14,904,704$ & $-61,627,970,099$ & 86,447 & 77,504 & 0.072 & 10,776 \\
\hline & Female & $16,977,059$ & $-75,291,558,959$ & 179,957 & 162,980 & 0.127 & 21,564 \\
\hline
\end{tabular}

LDCT low-dose computed tomography, $C X R$ chest X-ray, $Q A L Y$ s quality-adjusted life-years; $L Y$ s life expectancy life-years

this model does not estimate nonmedical indirect costs, such as reducing the burden on caregivers or reducing productivity. Finally, there are different screening costs and medical systems in each country. Further costeffectiveness studies by the variance of each country are required.

\section{Conclusions}

LDCT screening for never smokers has the greatest benefits and cost savings in Japan, but is not costeffective in the United States. LDCT screening reduces lung cancer deaths in never smokers in both countries and saves lives by early detection of adenocarcinomas, especially in never-smoking women. The findings support changing population-based lung cancer screening methods for never smokers from CXR or no screening to LDCT in high-incidence countries. Assessing the risk of lung cancer in never smokers is important for introducing population-based LDCT screening.

\section{Abbreviations}

LDCT: Low-dose computed tomography; CXR: Chest X-ray; QALY: Qualityadjusted life-year; LY: Life expectancy life-year; ICER: Incremental cost-effectiveness ratio; NSCLC: Non-small cell lung cancer; EV: Expected value.

\section{Acknowledgements}

None.

\section{Authors' contributions}

AK contributed to the study concept and design, data acquisition and analysis, interpretation of the data, accepted responsibility for the integrity of the research process and findings, and approved the final manuscript.

\section{Funding}

The author declares no funding support for this study.
Availability of data and materials

The datasets used and analyzed during the current study are available from the corresponding author on reasonable request.

\section{Declarations}

Ethics approval and consent to participate

Not applicable.

Consent for publication

Not applicable.

Competing interests

The author declares no competing interests.

\section{Author details}

${ }^{1}$ Department of Occupational Health, Kitasato University Graduate School of Medical Sciences, 1-15-1 Kitasato, Minami-ku, Sagamihara, Kanagawa 252-0373, Japan. ${ }^{2}$ Health Sciences University of Hokkaido, 1757 Kanazawa, Tobetsu-cho, Ishikari-gun, Hokkaido 061-0293, Japan.

Received: 9 August 2021 Accepted: 16 December 2021

Published online: 08 January 2022

\section{References}

1. World Cancer Research Fund International. Lung Cancer Statistics. 2019. https://www.wcrforg/dietandcancer/cancer-trends/lung-cancer-stati stics. Accessed 7 Aug 2021.

2. National Lung Screening Trial Research Team, Aberle DR, Adams AM, Berg CD, Black WC, Clapp JD, et al. Reduced lung-cancer mortality with low-dose computed tomographic screening. N Engl J Med. 2011;365:395-409.

3. The National Lung Screening Trial Research Team. Lung cancer incidence and mortality with extended follow-up in the National Lung Screening Trial. J Thorac Oncol. 2019;14:1732-42.

4. de Koning HJ, van der Aalst CM, de Jong PA, Scholten ET, Nackaerts $\mathrm{K}$, Heuvelmans MA, et al. Reduced lung-cancer mortality with volume CT screening in a randomized trial. N Engl J Med. 2020;382:503-13.

5. Moyer VA; U.S. Preventive Services Task Force. Screening for lung cancer: U.S. Preventive Services Task Force recommendation statement. Ann Intern Med. 2014; 160:330-8.

6. Steliga MA, Yang P. Integration of smoking cessation and lung cancer screening. Transl Lung Cancer Res. 2019;8:S88-94. 
7. Jaine R, Kvizhinadze G, Nair N, Blakely T. Cost-effectiveness of a low-dose computed tomography screening programme for lung cancer in New Zealand. Lung Cancer. 2018;124:233-40.

8. Hofer F, Kauczor HU, Stargardt T. Cost-utility analysis of a potential lung cancer screening program for a high-risk population in Germany: A modelling approach. Lung Cancer. 2018;124:189-98.

9. Criss SD, Cao P, Bastani M, Ten Haaf K, Chen Y, Sheehan DF, et al. Costeffectiveness analysis of lung cancer screening in the United States: a comparative modeling study. Ann Intern Med. 2019;171:796-804.

10. Snowsill T, Yang H, Griffin E, Long L, Varley-Campbell J, Coelho H, et al. Low-dose computed tomography for lung cancer screening in high-risk populations: a systematic review and economic evaluation. Health Technol Assess. 2018:22:1-276.

11. Wade S, Weber M, Caruana M, Kang YJ, Marshall H, Manser R, et al. estimating the cost-effectiveness of lung cancer screening with low-dose computed tomography for high-risk smokers in Australia. J Thorac Oncol. 2018;13:1094-105.

12. Goffin JR, Flanagan WM, Miller AB, Fitzgerald NR, Memon S, Wolfson MC, et al. Cost-effectiveness of lung cancer screening in Canada. JAMA Oncol. 2015;1:807-13.

13. $\mathrm{Ng} \mathrm{M}$, Freeman MK, Fleming TD, Robinson M, Dwyer-Lindgren $L$, Thomson B, et al. Smoking prevalence and cigarette consumption in 187 countries, 1980-2012. JAMA. 2014;311:183-92.

14. GBD 2015 Tobacco Collaborators. Smoking prevalence and attributable disease burden in 195 countries and territories, 1990-2015: a systematic analysis from the Global Burden of Disease Study 2015. Lancet. 2017; 389:1885-906.

15. Japanese Ministry of Health, Labor and Welfare. National Health and Nutrition Survey. http://www.health-net.or.jp/tobacco/product/pd100 000.html. Accessed 7 Aug 2021.

16. Bryant A, Cerfolio RJ. Differences in epidemiology, histology, and survival between cigarette smokers and never-smokers who develop non-small cell lung cancer. Chest. 2007:132:185-92.

17. Yano T, Miura N, Takenaka T, Haro A, Okazaki H, Ohba T, et al. Neversmoking nonsmall cell lung cancer as a separate entity: clinicopathologic features and survival. Cancer. 2008;113:1012-8.

18. Kang HR, Cho JY, Lee SH, Lee YJ, Park JS, Cho YJ, et al. Role of low-dose computerized tomography in lung cancer screening among neversmokers. J Thorac Oncol. 2019;14:436-44.

19. Sun S, Schiller JH, Gazdar AF. Lung cancer in never smokers-a different disease. Nat Rev Cancer. 2007;7:778-90.

20. Zhou F, Zhou C. Lung cancer in never smokers-the East Asian experience. Transl Lung Cancer Res. 2018;7:450-63.

21. National Cancer Center. Cancer Statistics in Japan, 2019. https://ganjo ho.jp/reg_stat/statistics/dl/index.html\#incidence4pref. Accessed 7 Aug 2021.

22. Japanese Ministry of Health, Labour and Welfare. Guidelines for lung cancer screening in Japan. May 24, 2018. https://www.mhlw.go.jp/conte nt/10901000/000487807.pdf. Accessed 7 Aug 2021.

23. Kakinuma R, Muramatsu Y, Asamura H, Watanabe SI, Kusumoto M, Tsuchida T, et al. Low-dose CT lung cancer screening in never-smokers and smokers: results of an eight-year observational study. Transl Lung Cancer Res. 2020:9:10-22.

24. Kondo R, Yoshida K, Kawakami S, Shiina T, Kurai M, Takasuna K, et al. Efficacy of CT screening for lung cancer in never-smokers: analysis of Japanese cases detected using a low-dose CT screen. Lung Cancer. 2011;74:426-32

25. Kawaguchi T, Matsumura A, Fukai S, Tamura A, Saito R, Zell JA, et al. Japanese ethnicity compared with Caucasian ethnicity and never-smoking status are independent favorable prognostic factors for overall surviva in non-small cell lung cancer: a collaborative epidemiologic study of the National Hospital Organization Study Group for Lung Cancer (NHSGLC) in Japan and a Southern California Regional Cancer Registry databases. J Thorac Oncol. 2010;5:1001-10.

26. Wakelee HA, Chang ET, Gomez SL, Keegan TH, Feskanich D, Clarke CA, et al. Lung cancer incidence in never smokers. J Clin Oncol. 2007:25:472-8

27. Cufari ME, Proli C, De Sousa P, Raubenheimer H, Al Sahaf M, Chavan H, et al. Increasing frequency of non-smoking lung cancer: presentation of patients with early disease to a tertiary institution in the UK. Eur J Cancer. 2017:84:55-9.
28. Sanders GD, Neumann PJ, Basu A, Brock DW, Feeny D, Krahn M, et al. Recommendations for conduct, methodological practices, and reporting of cost-effectiveness analyses: second panel on cost-effectiveness in health and medicine. JAMA. 2016;316:1093-103.

29. Japanese Lung Cancer Association. Japanese lung cancer treatment guidelines 2019. https://www.haigan.gr.jp/guideline/2019/1/2/19010 2000000.html. Accessed 7 Aug 2021.

30. Criss SD, Mooradian MJ, Sheehan DF, Zubiri L, Lumish MA, Gainor JF, et al. Cost-effectiveness and budgetary consequence analysis of Durvalumab consolidation therapy vs no consolidation therapy after Chemoradiotherapy in stage III non-small cell lung cancer in the context of the us health care system. JAMA Oncol. 2019;5:358-65.

31. Thomas A, Pattanayak P, Szabo E, Pinsky P. Characteristics and outcomes of small cell lung cancer detected by CT screening. Chest. 2018;154:1284-90.

32. Kyushu University Hospital Lung Cancer Registration Information. https:// www.gan.med.kyushu-u.ac.jp/result/lung_cancer/index7. Accessed 7 Aug 2021.

33. Igakutsushin-sya. National fee schedule and Medical insurance reimbursement table in Japan [in Japanese]. Tokyo: Igakutsushin-sya; 2018.

34. PPPs (Purchasing Power Parities) and exchange rates [Organisation for Economic Co-operation and Development (OECD)Web site]. 2019. https://stats.oecd.org/Index.aspx?datasetcode=SNA_TABLE4 Accessed 7 Aug 2021.

35. Kumar V, Cohen JT, van Klaveren D, Soeteman DI, Wong JB, Neumann PJ, et al. Risk-targeted lung cancer screening: a cost-effectiveness analysis. Ann Intern Med. 2018:168:161-9.

36. Centers for Medicare \& Medicaid Services. 2018 ASP Drug Pricing Files: ASP Drug Pricing Files October 2018 update. https://www.cms.gov/ Medicare/Medicare-Fee-for-Service-Part-B-Drugs/McrPartBDrugAvgSales Price/2018ASPFiles.html. Accessed 7 Aug 2021.

37. Sheehan DF, Criss SD, Chen Y, Eckel A, Palazzo L, Tramontano AC, et al. Lung cancer costs by treatment strategy and phase of care among patients enrolled in Medicare. Cancer Med. 2019;8:94-103.

38. Edejer TT-T, Baltussen R, Adam T, Hutubessy R, Acharya A, Evans DB, et al. Making choices in health: WHO guide to cost-effectiveness analysis. Geneva, Switzerland: World Health Organization. 2003;67-71.

39. Oken MM, Marcus PM, Hu P, Beck TM, Hocking W, Kvale PA, et al. Baseline chest radiograph for lung cancer detection in the randomized Prostate, Lung, Colorectal and Ovarian Cancer Screening Trial. J Natl Cancer Inst. 2005;97:1832-9.

40. Howlader N, Noone AM, Krapcho M, Miller D, Brest A, Yu M, et al. SEER Cancer Statistics Review, 1975-2017, National Cancer Institute. Bethesda, MD, https://seer.cancer.gov/csr/1975_2017/, based on November 2019 SEER data submission, posted to the SEER web site, April 2020. Accessed 7 Aug 2021.

41. National Lung Screening Trial Research Team, Church TR, BlackWC, Aberle $\mathrm{DR}$, Berg CD, Clingan KL, et al. Results of initial low-dose computed tomographic screening for lung cancer. N Engl J Med. 2013; 368:1980-91.

42. Perisinakis K, Seimenis I, Tzedakis A, Karantanas A, Damilakis J. Radiation burden and associated cancer risk for a typical population to be screened for lung cancer with low-dose CT: A phantom study. Eur Radiol. 2018:28:4370-8.

43. BEIR 7. National research council, committee on the biological effects of ionizing radiation. Health effects of exposure to low levels of ionizing radiation (BEIR VII phase 2). Washington, DC: National Academy Press; 2006.

44. Sturza J. A review and meta-analysis of utility values for lung cancer. Med Decis Mak. 2010;30:685-93.

45. Li LY, Wang H, Chen X, Li WQ, Cui JW. First-line atezolizumab plus chemotherapy in treatment of extensive small cell lung cancer: a cost-effectiveness analysis from China. Chin Med J. 2019;132:2790-4.

46. Neumann PJ, Cohen JT, Weinstein MC. Updating cost-effectiveness-the curious resilience of the $\$ 50,000$-per-QALY threshold. N Engl J Med. 2014;371:796-7.

47. Siegel DA, Fedewa SA, Henley SJ, Pollack LA, Jemal A. Proportion of never smokers among men and women with lung cancer in 7 US States. JAMA Oncol. 2021;7:302-4.

48. Chu ZG, Yang ZG, Shao H, Zhu ZY, Deng W, Tang SS, et al. Small peripheral lung adenocarcinoma: $\mathrm{CT}$ and histopathologic characteristics and prognostic implications. Cancer Imaging. 2011;11:237-46. 
49. Infante MV, Cardillo G. Lung cancer screening in never-smokers: facts and remaining issues. Eur Respir J. 2020;56:2002949.

50. Slatore CG, Sullivan DR, Pappas M, Humphrey LL. Patient-centered outcomes among lung cancer screening recipients with computed tomography: a systematic review. J Thorac Oncol. 2014;9:927-34.

51. Patz EF Jr, Pinsky P, Gatsonis C, Sicks JD, Kramer BS, Tammemägi MC, et al. Overdiagnosis in low-dose computed tomography screening for lung cancer. JAMA Intern Med. 2014;174:269-74.

52. Pinsky P, Gierada DS. Long-term cancer risk associated with lung nodules observed on low-dose screening CT scans. Lung Cancer. 2020;139:179-84.

53. Seijo LM, Peled N, Ajona D, Boeri M, Field JK, Sozzi G, et al. Biomarkers in lung cancer screening: achievements, promises, and challenges. JThorac Oncol. 2019;14:343-57.

54. Malhotra J, Malvezzi M, Negri E, La Vecchia C, Boffetta P. Risk factors for lung cancer worldwide. Eur Respir J. 2016;48:889-902.

55. Abdel-Rahman O. Incidence and mortality of lung cancer among never smokers in relationship to secondhand smoking: findings from the PLCO trial. Clin Lung Cancer. 2020;21:415-420.e2.

56. Cheng PC, Cheng YC. Correlation between familial cancer history and epidermal growth factor receptor mutations in Taiwanese never smokers with non-small cell lung cancer: a case-control study. J Thorac Dis. 2015;7:281-7.

57. Hori M, Tanaka H, Wakai K, Sasazuki S, Katanoda K. Secondhand smoke exposure and risk of lung cancer in Japan: a systematic review and metaanalysis of epidemiologic studies. Jpn J Clin Oncol. 2016;46:942-51.

58. Lorenzo-González M, Ruano-Ravina A, Torres-Durán M, Kelsey KT, Provencio M, Parente-Lamelas I, et al. Lung cancer and residential radon in never-smokers: a pooling study in the Northwest of Spain. Environ Res. 2019;172:713-8.

59. Lin $\mathrm{H}$, Huang $\mathrm{YS}$, Yan $\mathrm{HH}$, Yang $\mathrm{XN}$, Zhong WZ, Ye HW, et al. A family history of cancer and lung cancer risk in never-smokers: a clinic-based case-control study. Lung Cancer. 2015;89:94-8.

60. Chapman AM, Sun KY, Ruestow P, Cowan DM, Madl AK. Lung cancer mutation profile of EGFR, ALK, and KRAS: Meta-analysis and comparison of never and ever smokers. Lung Cancer. 2016;102:122-34.

61. Wu KL, Tsai YM, Lien CT, Kuo PL, Hung AJ. The roles of MicroRNA in lung cancer. Int J Mol Sci. 2019:20:1611.

\section{Publisher's Note}

Springer Nature remains neutral with regard to jurisdictional claims in published maps and institutional affiliations.

Ready to submit your research? Choose BMC and benefit from:

- fast, convenient online submission

- thorough peer review by experienced researchers in your field

- rapid publication on acceptance

- support for research data, including large and complex data types

- gold Open Access which fosters wider collaboration and increased citations

- maximum visibility for your research: over 100M website views per year

At BMC, research is always in progress.

Learn more biomedcentral.com/submissions 